\title{
ANÁLISE DO GRAU DE CRISTALINIDADE DA ESCÓRIA DA ARCELORMITTAL TUBARÃO
}

Silva, M. F. ${ }^{1 *}$; Orlando, M. T. D. ${ }^{1}$; Dieguez, A. C. O. ${ }^{2}$; Moreira, R. F. T. ${ }^{2}$; Magalhães, D. C. ${ }^{3}$; Martins, J. B. R. ${ }^{3}$.

1 Programa de Pós-Graduação em Engenharia Mecânica, Universidade Federal do Espírito Santo, Vitória, E.S., Brasil. 2 ArcelorMittal Tubarão, Serra, E.S., Brasil.

3 Global R\&D Brazil - ArcelorMittal, Serra, E.S., Brasil

* e-mail: marllon.1@hotmail.com

\section{Resumo}

Com o objetivo de analisar o grau de cristalinidade da escória de alto forno, foram coletadas quatro amostras oriundas da empresa ArcelorMittal Tubarão. As amostras foram posteriormente maceradas e passadas por uma peneira de $100 \mu \mathrm{m}$, para que fossem analisadas pelo método de difração de raios $\mathrm{X}$. Com o resultado desta análise de difração, identificou-se que o material possuía uma grande quantidade de fase amorfa (cerca de $90 \%$ da amostra) e, a partir da subtração desta fase, obteve-se a fase cristalina, correspondendo a $10 \%$ da escória. O amorfo é composto, em quase sua totalidade, por dióxido de silício $\left(\mathrm{SiO}_{2}\right)$ e óxido de cálcio $(\mathrm{CaO})$, e a parte cristalina do material é composta basicamente por quatro tipos de componentes $\left(\mathrm{Fe}_{3} \mathrm{C}, \mathrm{MgFe}_{2} \mathrm{O}_{4}, \mathrm{Fe}_{2} \mathrm{SiO}_{4}, \mathrm{Fe}_{2} \mathrm{O}_{3} ! \mathrm{H}_{2} \mathrm{O}\right)$. Futuros estudos serão feitos para determinar se o resultado trata-se de um caso geral ou se ocorreu especificamente no lote analisado.

\begin{abstract}
In order to analyze the degree of crystallinity of blast furnace slag, four samples were collected from Arcelor Mittal Tubarão. The samples were then macerated and passed through a $100 \mu \mathrm{m}$ sieve so that they could be analyzed by the X-ray diffraction method. With the result of this diffraction analysis, it was identified that the material had a large amount of amorphous phase (around $90 \%$ of the sample) and, from the subtraction of this phase, the crystalline phase, corresponding to $10 \%$ of the slag, was obtained. Amorphous is composed almost entirely of silicon dioxide $\left(\mathrm{SiO}_{2}\right)$ and calcium oxide $(\mathrm{CaO})$, and the crystalline part of the material is composed basically of four types of components $\left(\mathrm{Fe}_{3} \mathrm{C}, \mathrm{MgFe}_{2} \mathrm{O}_{4}\right.$, $\mathrm{Fe}_{2} \mathrm{SiO}_{4}, \mathrm{Fe}_{2} \mathrm{O}_{3} ! \mathrm{H}_{2} \mathrm{O}$ ). Future studies will be conducted to determine whether the result is a general case or whether it occurred specifically in the analyzed batch.
\end{abstract}

Keywords: Amorphous, Crystal, Slag, X-ray diffraction.

\section{Introdução}

Escórias básicas são utilizadas nas indústrias de aglomerantes há décadas, sendo que, em 1862 (em Troisdord - França) Eugene Langen realizou os primeiros ensaios que se tem notícia sobre a granulação das escórias (vitrificadas), comprovando que a partir destas escórias básicas, moídas e misturadas com cal hidráulica advinha um material que não possuía a qualidade do cimento Portland, porém já superava os sistemas que utilizavam apenas cal como ligante. $^{[1]}$

Essa escória utilizada como aglomerante é um coproduto do processo siderúrgico, onde tem-se a 
transformação do minério e coque em ferro gusa e posteriormente em aço. A fabricação deste ferro gusa é realizada em unidades industriais chamadas AltosFornos, nas quais se reduz os óxidos contidos nos minerais de ferro e separa-se as impurezas que os acompanha. ${ }^{[2]}$

A fusão das impurezas do minério de ferro, juntamente com a adição de fundentes (calcário e dolomita) e as cinzas do coque (carvão mineral), dão origem à produção da escória. Quando fundida, a escória apresenta insolubilidade e menor densidade que o ferro gusa. Como consequência, ela irá sobrenadar no ferro gusa, facilitando a sua retirada do alto forno através dos canais, sendo então encaminhada para um local de resfriamento. $^{[2]}$

A composição química das escórias de alto forno obtidas sob a forma granular tem como principal constituinte o óxido de silício $\left(\mathrm{SiO}_{2}\right)$, óxido de alumínio $\left(\mathrm{Al}_{2} \mathrm{O}_{3}\right)$, óxido de cálcio $(\mathrm{CaO})$ e óxido de magnésio (MgO), que correspondem a aproximadamente 97,3\% do total da escória. Pode-se dizer que as escórias de alto forno são rochas metamórficas tipo silicíticas, levemente ácidas, com significativo teor de óxidos de cálcio e magnésio. ${ }^{[2][3]}$

Na tabela 1, observa-se a composição química da escória da ArcelorMittal Tubarão. Já na tabela 2 tem-se um exemplo de composição química da escória, que foi caracterizada pelo Centro de Nanotecnologia da Universidade Técnica de Ostrava, na República Tcheca. Comparando as tabelas, pode-se afirmar que a quantidade dos óxidos de ambas as escórias, apresentam proporções semelhantes em massa.

\begin{tabular}{|c|c|c|}
\hline Materiais & $\begin{array}{c}\text { Unidade de } \\
\text { Medida } \\
\end{array}$ & $\begin{array}{l}\text { Resultado da } \\
\text { determinação }\end{array}$ \\
\hline $\mathrm{CaO}$ & $\%$ & 41,6 \\
\hline $\mathrm{MgO}$ & $\%$ & 7,95 \\
\hline $\mathrm{SiO}_{2}$ & $\%$ & 33,65 \\
\hline $\mathrm{Al}_{2} \mathrm{O}_{3}$ & $\%$ & 12,42 \\
\hline
\end{tabular}

Nota: Dados adaptados pelo autor.
Tabela 2: Composições químicas típicas das escórias de alto forno da

\begin{tabular}{lcr}
\multicolumn{3}{c}{ Universidade Técnica de Ostrava } \\
\hline $\mathrm{CaO}$ & $\begin{array}{c}\text { Unidade de } \\
\text { Medida }\end{array}$ & $\begin{array}{r}\text { Resultado da } \\
\text { determinação }\end{array}$ \\
$\mathrm{MgO}$ & $\%$ & 36,3 \\
$\mathrm{SiO}_{2}$ & $\%$ & 11,7 \\
$\mathrm{Al}_{2} \mathrm{O}_{3}$ & $\%$ & 42,5 \\
$\mathrm{Fe}_{2} \mathrm{O}_{3}$ & $\%$ & 6,8 \\
$\mathrm{SO}_{3}$ & $\%$ & 0,18 \\
$\mathrm{~K}_{2} \mathrm{O}_{\mathrm{Cl}}$ & $\%$ & 1,56 \\
$\mathrm{Cl}_{\mathrm{Sr}}$ & $\mu \mathrm{g} \cdot \mathrm{g}^{-1}$ & 0,36 \\
$\mathrm{Ba}$ & $\mu \mathrm{g} \cdot \mathrm{g}^{-1}$ & 156,6 \\
& $\mu \mathrm{gg} \cdot \mathrm{g}^{-1}$ & 377,3 \\
& Fonte: Václavík (2012).
\end{tabular}

Nota: Dados adaptados pelo autor.

As propriedades fundamentais das escórias dependem da hidraulicidade, ou seja, da capacidade ou não de alguns de seus óxidos reagirem em meio saturado, formando sais insolúveis e estáveis. Esta por sua vez depende de sua composição química e principalmente da sua forma de obtenção, seja no estado sólido amorfo resfriado ou no estado sólido cristalino resfriado. ${ }^{[1]}$

A composição mineralógica da escória de alto forno, varia de acordo com o tipo de resfriamento. Quando é submetida ao resfriamento rápido, a escória será de composição majoritariamente amorfa, neste caso está apta para ser utilizada como aditivos ou ligantes hidráulicos que, devido ao seu comportamento termodinâmico instável e hidraulicamente latente pode ser ativada. Quando o resfriamento ocorre de forma lenta, a constituição será majoritariamente cristalina, apta para ser utilizada como agregado. Isso ocorre devido à carência das propriedades hidráulicas e estabilidade termodinâmica. ${ }^{[1]}$

Em suma, a característica mais importante da escória usada como aglomerante é a sua capacidade hidráulica potencial. Desta forma ela possibilita que, quando moída e em contato com a água, a escória endureça, podendo substituir parte do clínquer Portland, na fabricação de cimentos compostos. ${ }^{[2]}$ 


\section{Método Experimental}

Com o objetivo de analisar o grau de cristalinidade da escória de alto forno, foram coletadas quatro amostras oriundas da empresa ArcelorMittal Tubarão. As amostras foram posteriormente maceradas e peneiradas em $100 \mu \mathrm{m}$, para que assim, o material passante na peneira fosse analisado pelo método de difração de raios $X$.

Essa escória em forma de pó foi analisada por difração de raios $\mathrm{X}$, com o uso da máquina Rigaku, modelo Ultima IV. A radiação usada na difração foi a de cobre (Cu K-alpha) e seu comprimento de onda de $0.15420 \mathrm{~nm}$, passo de $0.02^{\circ}$, tempo de 2 s e potência de $800 \mathrm{kw}$. Essa radiação do cobre iluminou as amostras e então foi obtido o padrão em função da difração.

Avaliando o padrão de difração, identificou-se que o material possuía uma grande quantidade de fase amorfa, representando cerca de $90 \%$ em massa da amostra. Porém, para descobrir a composição do restante da amostra, foi feita a subtração do padrão da fase amorfa, obtendo-se assim um padrão residual relacionado à fase cristalina, que corresponde à $10 \%$ em massa da escória.

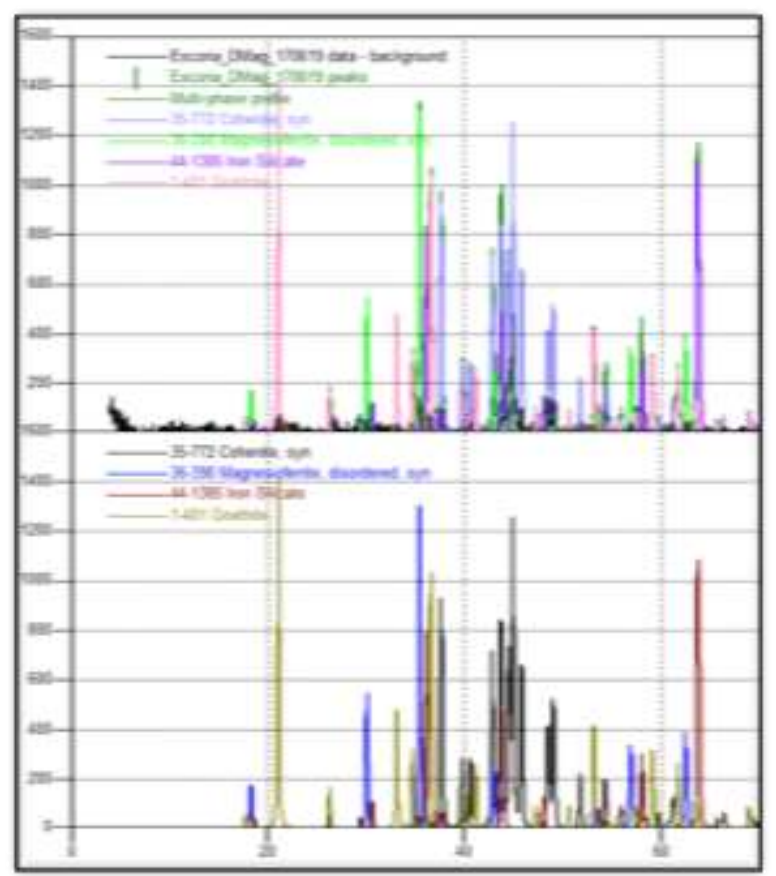

Figura 1: Resultado da análise de difração de raios $X$ da escória
Na figura 1 tem-se o resultado da análise de difração de raios $X$ na escória. $\mathrm{Na}$ primeira parte tem-se a amostra total, contendo a fase amorfa e cristalina. Com a subtração do padrão da fase amorfa é obtida a segunda parte do gráfico, que revela apenas a parte cristalina da escória. A difração de raios $X$ foi feita com o ângulo $2 \theta$ variando de $0^{\circ}$ até $140^{\circ}$, porém com intuito de facilitar a visualização dos resultados, o ângulo $2 \theta$ foi ajustado variando de $0^{\circ}$ até $70^{\circ}$, tendo em vista que essa mudança não influência na interpretação da análise de difração, uma vez que, nesta faixa identifica-se as principais informações.

\section{Resultados e Discussão}

A partir da análise dos dados da difração de raios $X$, pode-se verificar (Fig. 01) que os materiais que compõem a fase cristalina da escória são a Cohenita, conhecida também como Cementita, Magnesioferrita, Silicato de ferro e Goethita. As tabelas 3, 4, 5 e 6 mostram de forma detalhada os parâmetros dos materiais da fase cristalina.

\begin{tabular}{ll}
\multicolumn{2}{c}{ Tabela 3: Parâmetros da Cohenita/Cementita } \\
\hline \multicolumn{2}{c}{ A Cohenite, syn } \\
\hline Formula & Fe3 C \\
Pdf Number & $35-772$ \\
Figure of Merit & $34 \%$ \\
Total Peaks & 49 \\
Peaks Matched & 33 \\
New Matches & 33 \\
Strong Unmatched & 0 \\
Peak Shift & 0 \\
Scale Factor & 0.739721 \\
Concentration & Not available \\
\hline & \\
\multicolumn{2}{c}{ Tabela 4: Parâmetros da Magnesioferrita } \\
\hline \multicolumn{1}{c}{ B Magnesioferrite, disordered, syn } \\
\hline Formula & Mg Fe2 O4 \\
Pdf Number & $36-398$ \\
Figure of Merit & $23 \%$ \\
Total Peaks & 25 \\
Peaks Matched & 9 \\
New Matches & 8 \\
Strong Unmatched & 0 \\
Peak Shift & 0 \\
Scale Factor & 0.296087 \\
Concentration & Not available \\
\hline
\end{tabular}


Tabela 5: Parâmetros do Silicato de Ferro

\begin{tabular}{|c|c|}
\hline \multicolumn{2}{|c|}{ C Iron Silicate } \\
\hline Formula & Fe2 Si O4 \\
\hline Pdf Number & $44-1385$ \\
\hline Figure of Merit & $14 \%$ \\
\hline Total Peaks & 9 \\
\hline Peaks Matched & 6 \\
\hline New Matches & 2 \\
\hline Strong Unmatched & 0 \\
\hline Peak Shift & 0 \\
\hline Scale Factor & 0.0456147 \\
\hline Concentration & Not available \\
\hline \multicolumn{2}{|c|}{ Tabela 6: Parâmetros do Goethita } \\
\hline \multicolumn{2}{|c|}{ D Goethite } \\
\hline Formula & $\mathrm{Fe} 2 \mathrm{O} 3$ ! $\mathrm{H} 2 \mathrm{O}$ \\
\hline Pdf Number & $1-401$ \\
\hline Figure of Merit & $14 \%$ \\
\hline Total Peaks & 20 \\
\hline Peaks Matched & 8 \\
\hline New Matches & 7 \\
\hline Strong Unmatched & 0 \\
\hline Peak Shift & 0 \\
\hline Scale Factor & 0.141155 \\
\hline Concentration & Not available \\
\hline
\end{tabular}

Duas discussões devem ser feitas através dos resultados obtidos na análise detalhada do padrão de difração de raios $X$. A primeira, acerca da importância do grau de cristalinidade da escória. Considerando a redução da quantidade de amorfo, e consequente redução da reatividade total da escória, fator importante no uso da mesma como aglomerante, é importante um estudo detalhado com o objetivo de verificar a recorrência destes resultados ou aleatoriedade dos mesmos, pois a variação do grau de cristalinidade está relacionada com a velocidade de resfriamento da escória fundida. Concluindo, pode-se associar que estes resultados podem estar indicando a ocorrência de mudanças nos parâmetros de produção da escória. Uma segunda discussão importante baseia-se na possibilidade do uso destes materiais cristalinos em outras aplicações tecnológicas, sendo necessário, no entanto, a confirmação da representatividade dos resultados obtidos.

\section{Conclusão}

Conclui-se que através da análise do padrão de difração de raios $X$ da escória, identificou-se que o material possuía uma grande quantidade de fase amorfa (cerca de $90 \%$ em massa da amostra) e, a partir da subtração desta fase, obteve-se a fase cristalina, correspondente a $10 \%$ em massa da escória. O amorfo é composto, em quase sua totalidade, por dióxido de silício $\left(\mathrm{SiO}_{2}\right)$ e óxido de cálcio $(\mathrm{CaO})$, sendo que a parte cristalina do material é composta basicamente por quatro tipos de componentes $\left(\mathrm{Fe}_{3} \mathrm{C}\right.$, $\mathrm{MgFe}_{2} \mathrm{O}_{4}, \mathrm{Fe}_{2} \mathrm{SiO}_{4}, \mathrm{Fe}_{2} \mathrm{O}_{3} ! \mathrm{H}_{2} \mathrm{O}$ ) já detalhados neste trabalho.

Futuros estudos serão feitos para determinar se o resultado obtido trata-se de um caso geral ou ocorreu especificamente no lote analisado. Além disso, é preciso verificar a variação do grau de cristalinidade, com o objetivo de identificar flutuações deste valor em outras amostras.

\section{Agradecimentos}

Os autores agradecem a ArcelorMittal Tubarão e a Global R\&D Brazil - ArcelorMittal pelo apoio e contribuição no desenvolvimento da pesquisa.

\section{Referências}

[1] MOREIRA, C. C.. Características e Desempenho da Escória de Alto Forno como Agregado para Utilização em Camadas Granulares de Pavimento, 2006. 37ª

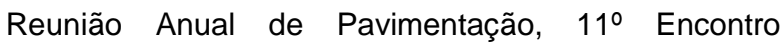
Nacional de Conservação Rodoviária, 37ª RAPv/11ํำ ENACOR, N¹03, Goiânia-GO, 2006.

[2] THOMAZ, E. C. S.. Escória de Alto Forno - Parte 1 - Fabricação. Instituto Militar de Engenharia, Rio de Janeiro-RJ.

[3] VÁCLAVÍK, V.; DIRNER, V.; DVORSKÝ, T.; DAXNER, J.. The Use of Blast Furnace Slag, 2012. $\begin{array}{lllll}\text { Metalurgia } & 51 & (2012) & 4, & \text { p. }\end{array}$ 